University of Warwick institutional repository: http://go.warwick.ac.uk/wrap

This paper is made available online in accordance with publisher policies. Please scroll down to view the document itself. Please refer to the repository record for this item and our policy information available from the repository home page for further information.

To see the final version of this paper please visit the publisher's website. Access to the published version may require a subscription.

Author(s): McWilliams, D. F., Doherty, S. A., Jenkins, W. D., Maciewicz, R. A., Muir, K. W., Zhang, W. and Doherty, M.

Article Title: Mild acetabular dysplasia and risk of osteoarthritis of the hip : a case-control study

Year of publication: 2010

Link to published article:

http://dx.doi.org/10.1136/ard.2009.127076

Publisher statement: None 


\title{
Mild acetabular dysplasia and risk of osteoarthritis of the hip: a case-control study
}

\author{
Daniel F McWilliams, ${ }^{1}$ Sally A Doherty, ${ }^{1}$ Wendy D Jenkins, ${ }^{1}$ Rose A Maciewicz, ${ }^{2}$ \\ Kenneth R Muir, ${ }^{3}$ Weiya Zhang, ${ }^{1}$ Michael Doherty ${ }^{1}$
}

\begin{abstract}
${ }^{1}$ Academic Rheumatology, University of Nottingham, Nottingham, UK

${ }^{2}$ AstraZeneca UK, Loughborough, UK ${ }^{3}$ Health Sciences Research Institute, University of Warwick, Coventry, UK
\end{abstract}

\section{Correspondence to}

Daniel McWilliams, Academic Rheumatology, Clinical Sciences Building, City Hospital, Nottingham NG5 1PB, UK; dan.mcwilliams@nottingham. ac.uk

Accepted 16 February 2010

\begin{abstract}
Objective To determine whether mild variation in acetabular depth (AD) and shape is a risk factor for osteoarthritis (OA) of the hip.

Methods The unaffected contralateral hip of patients with unilateral hip OA was compared with hips of asymptomatic controls without hip OA, derived from the Nottingham Genetics Osteoarthritis and Lifestyle case-control study. Standardised anteroposterior $x$-rays of the pelvis were used to measure centre edge (CE) angle and $\mathrm{AD}$. Cut-off points for narrow $\mathrm{CE}$ angle and shallow $A D$ were calculated from the control group (mean $-1.96 \times \mathrm{SD}$ ). The relative risk of hip $\mathrm{OA}$ associated with each feature was estimated using $\mathrm{OR}$ and $95 \% \mathrm{Cl}$ and adjusted risks were calculated by logistic regression.
\end{abstract}

Results In controls, both the $\mathrm{CE}$ angle and the $\mathrm{AD}$ were lower in the left hip than in the right hip. The CE angle related to age in both hips, and $\mathrm{AD}$ of the right hip was lower in men than in women. The contralateral unaffected hip in patients with unilateral hip OA had a decreased $C E$ angle and $A D$ compared with controls, irrespective of side. The lowest tertile of the CE angle in contralateral hips was associated with an eightfold risk of $\mathrm{OA}$ (aOR $8.06,95 \% \mathrm{Cl} 4.87$ to 13.35 ) and the lowest tertile of $A D$ was associated with a 2.5 -fold risk of OA (aOR 2.53, 95\% Cl 1.28 to 5.00). Significant increases in the risk of $\mathrm{OA}$ were also found as the $C E$ angle and $A D$ decreased. Conclusion Constitutional mild acetabular dysplasia appears to increase the risk of hip OA.

\section{INTRODUCTION}

Osteoarthritis $(\mathrm{OA})$ of the hip is a common cause of pain and disability in later life. ${ }^{1}$ The causes of hip OA appear to be heterogeneous with constitutional, genetic and environmental risk factors influencing development of the disease. Heritability estimates for hip OA have been placed at 0.6 in women, ${ }^{2}$ although the mechanisms that predispose to hip OA are unknown. Other known risk factors include severe developmental dysplasia of the hip that often presents in childhood, ${ }^{3}{ }^{4}$ occupational activities, ${ }^{5}$ Legg-Calvé-Perthes disease, ${ }^{6}$ obesity $^{5}$ and ageing. ${ }^{5}$

Mild hip dysplasia is a possible cause of adultonset hip OA with a plausible biomechanical mechanism. Subtle differences in hip morphology between individuals may be asymptomatic, but could alter the biomechanical characteristics of the joint and contribute to OA. Geometric measures of hip morphology taken from x-rays, such as acetabular depth (AD) and centre edge (CE) angle, have been investigated previously in OA with varying results. Two systematic reviews by Lievense et al concluded that there was limited evidence for dysplasia increasing incident hip $O A,{ }^{7}$ mostly based upon findings of one study, ${ }^{38}$ and limited evidence of no effect on progression, ${ }^{9}$ mostly based on one other study. ${ }^{10}$ Cross-sectional studies in Western European populations have supported an association between hip dysplasia and hip OA. Jacobsen found an association between hip $\mathrm{OA}$ and $\mathrm{CE}$ angle in the Osteoarthrosis substudy of the Copenhagen Heart Study. ${ }^{11}{ }^{12}$ In a 6-year follow-up study of 835 patients from the Netherlands, Reijman et al noted that the incidence of hip OA was related to both $\mathrm{CE}$ angle and $\mathrm{AD} \cdot{ }^{13}$ Jessel et al used MRI to show that patients with acetabular dysplasia had less cartilage and were more likely to have hip OA. ${ }^{14}$ Hip dysplasia has also been reported to cause new presentations of hip pain in one UK study, ${ }^{15}$ but not in another study of adults in Copenhagen. ${ }^{12}$ Some studies have also failed to link hip dysplasia and OA, including a radiographic assessment of 1315 men $^{16}$ and another of 393 women. ${ }^{4}$ Geographical variations have been reported in hip OA and its relationship to mild dysplasia. Japanese, ${ }^{17}{ }^{18}$ African, ${ }^{19} 20$ Turkish ${ }^{21}$ and $\mathrm{Sami}^{22}$ populations appear to have different prevalences of hip OA and acetabular dysplasia, and different associations than in Western Europeans. A caveat of many cross-sectional studies is that the measures of dysplasia are often undertaken on hips with established OA and could be secondary to $\mathrm{OA}$ and remodelling rather than being a pre-existing primary risk factor for its development.

Our group reported recently that non-spherical femoral head shape and shallow neck shaft angle were both more common in the contralateral unaffected hip of patients with unilateral hip OA than in non-OA controls in the Genetics of Osteoarthritis and Lifestyle (GOAL) study group. ${ }^{23}$ The unaffected hip is likely to be representative of the individual's joint morphology before the onset of $\mathrm{OA}$, and a study of the contralateral unaffected hip is a useful strategy for estimating risks of development of OA in cross-sectional studies. GOAL is a hospital-based case-control study primarily designed to investigate genetic and environment effects in patients with severe OA of the knee and/or hip sufficient to warrant consideration of joint replacement surgery. ${ }^{23-26}$ Young patients $(<45$ years) and those with known hip disease or dysplasia identified in childhood were excluded from GOAL, making it suitable for analysis of morphological factors that may increase the risk of common adult-onset hip OA. The objective of this study was to determine in the GOAL cohort ${ }^{23}$ whether acetabular dysplasia may be a risk factor for clinically severe adult-onset hip OA. 


\section{METHODS}

\section{Cases and controls}

Participants were men and women aged $>45$ years originally recruited in Nottingham, UK, between 2002 and 2006 to participate in the GOAL case-control study. Recruitment details have been published previously. ${ }^{23-26}$

Patients with hip OA were recruited from hospital orthopaedic surgery lists (current and from the previous 5 years) and from a rheumatology OA clinic. All cases had been referred to the hospital with symptomatic clinically severe hip OA and most had undergone unilateral or bilateral total hip replacement within the previous 5 years. Subjects were excluded from the study if they had other major arthropathy (eg, rheumatoid arthritis or ankylosing spondylitis), Paget's disease of bone affecting the pelvis or femur, overt childhood hip disease (eg, Legg-Calvé-Perthes, slipped femoral epiphysis or severe acetabular dysplasia), polio, total hip replacement due to trauma or avascular necrosis of the femoral head or a terminal illness. All control subjects were recruited from lists of people who had been referred to hospital for intravenous urography (IVU) within the last 5 years and had responded to a written invitation to participate in GOAL. Individuals who had no radiographic evidence of hip OA on their screening IVU radiograph and who had no hip or knee symptoms or any of the exclusions listed above for cases were invited to take part in the study (and undergo further standardised radiography) in writing and with a telephone call which provided further information and screening for exclusions. Cases and controls were further characterised by interview at home and examination at Academic Rheumatology, Nottingham.

Height and weight were measured to calculate body mass index (BMI). The presence of interphalangeal nodes was determined clinically by established methods, ${ }^{27} 28$ and a nodal phenotype was defined as Heberden and/or Bouchard nodes that affected at least two rays of each hand. A history of hip injury was defined as any self-reported significant hip injury (fracture, severe trauma requiring medical attention, immobilisation or crutches for $\geq 2$ weeks) due to occupation, sport or leisure activities during the subject's lifetime. Previous hip pain on most days for at least 1 month was also reported.

\section{Radiographic assessment of hips}

For cases that had undergone total hip replacement, the preoperative x-ray was copied using Hipax Dicom digitising software (Hipax, Vorstetten, Germany) to enable scoring. In cases who had not undergone total hip replacement and in all controls, new $\mathrm{x}$-rays were obtained unless the subject had undergone radiography of the pelvis (using the same standardised method) not more than 2 years previously.

Anteroposterior views of the pelvis were obtained using a standardised protocol ${ }^{23}$ with the participant supine and feet internally rotated $10^{\circ}(70 \mathrm{kV}$ exposure, broad focus, $100 \mathrm{~cm}$ focus-to-film distance). A single observer (SAD) measured the minimum joint space width (JSW) in $\mathrm{mm}$. A second observer (WDJ) measured the CE angle and $\mathrm{AD}$ according to the methods of Wiberg ${ }^{29}$ and Murray ${ }^{30}$ (figure 1). Each film was scanned and written to CD using the Hipax Dicom 4.2 x-ray image processor. CD images were read using the Hipax Private Health disc image viewer which enables straight line measurements between visually determined points to an accuracy of 0.01 $\mathrm{mm}$ and measurement of angles to an accuracy of $1^{\circ}$ (manufacturer precision). Repeatability was estimated from 25 pelvic $\mathrm{x}$-rays (7 non-OA and 18 hip OA cases) which were chosen
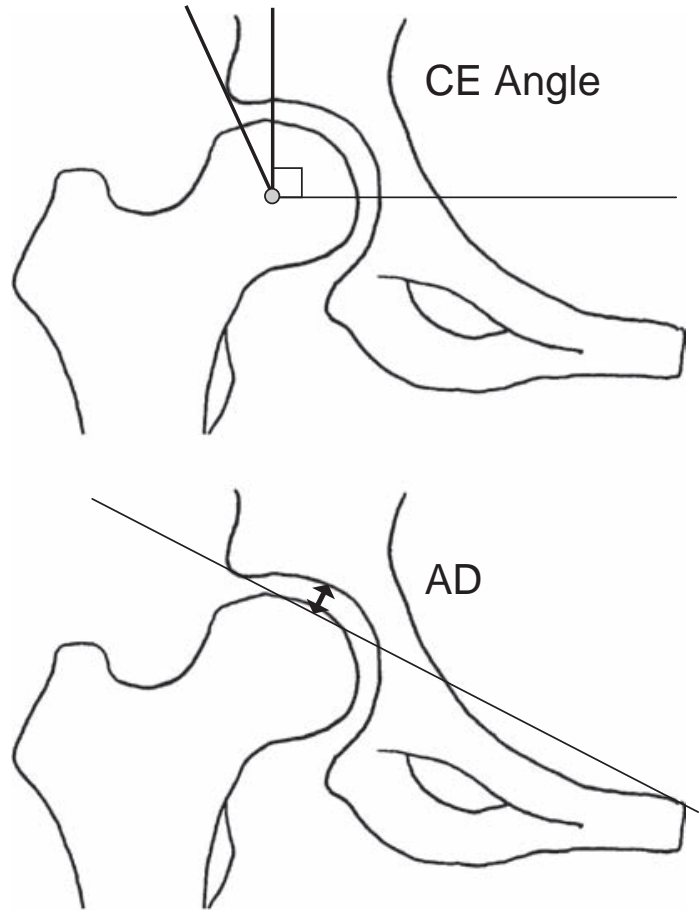

Figure 1 Measures of acetabular depth (AD) and centre edge (CE) angle. The diagram shows the guidelines used during measurement of $A D$ and $C E$ angle on hip x-rays.

from randomly assigned study numbers and assessed twice by each observer (WDJ/SAD). The 25 pelvic x-rays were comparable to the numbers that demonstrated repeatability in our previous studies, which were 24 pelvic $^{23}$ and 30 hand ${ }^{25} \mathrm{x}$-rays. Repeat measurements were performed by each observer (JSW: $\mathrm{SAD}$; CE angle and AD: WDJ) and the cases and controls were mixed together in the order of the randomly assigned study number. The x-rays were examined after the GOAL study sample collection had been completed and without a long time lag between each session of measurement. Radiographic hip OA was defined as a JSW $\leq 2.5 \mathrm{~mm},{ }^{23}$ and subjects in the case group with JSW $\leq 2.5 \mathrm{~mm}$ in one hip only were classified as having unilateral hip OA. Subjects in the control group with JSW $>2.5 \mathrm{~mm}$ in both hips were retained as non-OA controls for this study.

\section{Statistical analysis}

Repeatability of CE angle, AD and JSW were examined with intraclass coefficients (ICCs). Symmetry of these measures between left and right hips was examined in the control group. The prevalence of abnormal $\mathrm{CE}$ angle and $\mathrm{AD}$ was estimated using the cut-off values determined by mean $-1.96 \times \mathrm{SD}$ of each measure in the control population. In addition, we also used the standard thresholds found in the literature (CE angle $20^{\circ}, \mathrm{AD}$ $9 \mathrm{~mm})^{31216}$ for comparison purposes. The comparison between cases and control was undertaken separately for right and left hips. Differences between continuous measures were examined using the Student t test or paired t test and correlations were examined with the Pearson correlation coefficient. Dichotomous data were analysed with a $\chi^{2}$ test, or the McNemar test when comparing two dichotomous paired variables. Logistic regression analysis was used to adjust confounding factors, hips (right/left), age (tertiles), gender (female/male) and BMI (>25/ $\leq 25)$. Only one hip was used from controls on the basis of a random selection between right and left for each individual in the control group. 


\section{RESULTS}

\section{Demographic characteristics}

The demographic characteristics of the study group are shown in table 1. Cases of unilateral hip OA $(n=566)$ from the GOAL case-control study hip OA group were selected using the above criteria (minimum JSW $\leq 2.5 \mathrm{~mm})^{23}$ and non-OA controls $(\mathrm{n}=1108)$ had no radiographic $O A$ in either hip and no current hip pain; $7 \%(78 / 1108)$ reported previous hip pain. The unilateral hip OA group comprised $232(41 \%)$ right hips and $334(59 \%)$ left hips and had a higher mean age and BMI as well as more reported hip injuries and Heberden/Bouchard nodes. Neither the $\mathrm{AD}$ nor the $\mathrm{CE}$ angle (on either side) differed significantly between control participants with right or left dominant hands (data not shown). The response rates from the eligible populations of cases and controls were $68 \%$ and $65 \%$, respectively.

\section{Repeatability of measurements}

The ICC was used to assess the intraobserver variability of the $\mathrm{CE}$ angle and $\mathrm{AD}$. Both measures were found to have good repeatability (CE angle: ICC $0.76,95 \%$ CI 0.50 to 0.90 ; AD: ICC $0.79,95 \%$ CI 0.55 to 0.91 ), as did minimum JSW (ICC $0.98,95 \%$ CI 0.95 to 0.99 ).

\section{Characterisation and asymmetry in the non- $0 \mathrm{~A}$ controls}

The non-OA control group was used to examine the symmetry of normal hip morphology for $\mathrm{CE}$ angle and $\mathrm{AD}$. Mean $\mathrm{CE}$ angle and $\mathrm{AD}$ were significantly lower in right hips than in left hips

Table 1 Demographic characteristics of the study groups

\begin{tabular}{lll}
\hline & Non-OA controls & Unilateral hip 0A \\
\hline $\mathrm{N}$ & 1108 & 566 \\
Age & $64.2 \pm 8.4$ & $67.4 \pm 7.2^{* *}$ \\
Women (\%) & 46.3 & 47.9 \\
BMI & $27.5 \pm 4.6$ & $29.3 \pm 5.0^{* *}$ \\
Finger nodes (\%) & 12.0 & $26.1^{* *}$ \\
Hip injury (\%) & 2.0 & $7.8^{* *}$ \\
\hline
\end{tabular}

Mean \pm SD or prevalences are shown.

**p $<0.01$.

$B M I$, body mass index; $O A$, osteoarthritis. of the non-OA controls (table 2). The mean difference between right and left $\mathrm{CE}$ angles was $0.81^{\circ}(\mathrm{p}<0.01)$ and between $\mathrm{ADs}$ was $0.36 \mathrm{~mm}(p<0.01)$. Right and left hips were therefore analysed separately to control for the asymmetry. The $\mathrm{CE}$ angles were similar between genders while the right hips of men had lower $\mathrm{AD}$ than the right hips of women $(13.25 \mathrm{~mm}$ vs $13.63 \mathrm{~mm}$, $\mathrm{p}=0.038$; table 2 ). The $\mathrm{CE}$ angle was strongly correlated with $\mathrm{AD}$ (right: $\mathrm{r}=0.71, \mathrm{p}<0.001$; left: $\mathrm{r}=0.70, \mathrm{p}<0.001$ ) and very weakly related to age (right: $r=0.092, p=0.002$; left: $r=0.091, p=0.002$ ). However, $\mathrm{AD}$ showed no relationship with age (right: $\mathrm{r}=-0.04$, $\mathrm{p}=0.249$; left: $\mathrm{r}=-0.03, \mathrm{p}=0.381$ ).

According to mean $-1.96 \times \mathrm{SD}$ in the control group, the thresholds for $\mathrm{CE}$ angle were $24.6^{\circ}$ for the right hip and $25.7^{\circ}$ for the left hip, while those for $\mathrm{AD}$ were $7.47 \mathrm{~mm}$ for the right hip and $7.83 \mathrm{~mm}$ for the left hip. The proportions of non-OA controls classified as 'dysplastic' by exceeding the limits of our criteria or standard criteria found in the literature ( $\mathrm{CE}$ angle $20^{\circ}, \mathrm{AD} 9 \mathrm{~mm}$ ) are shown in table 2 .

\section{Risk of hip OA}

The mean CE angle was significantly lower in the unaffected contralateral hips of participants with unilateral hip OA than in controls (mean \pm SD $33.4 \pm 7.5$ vs $37.1 \pm 6.4, p<0.001$ for right hip; $33.4 \pm 8.1$ vs $37.9 \pm 6.2, p<0.001$ for left hip). The mean $\mathrm{AD}$ was also significantly lower in contralateral hips (mean \pm SD $11.7 \pm 3.0$ vs $13.4 \pm 3.0$, $\mathrm{p}<0.001$ for right hip; $12.1 \pm 3.4$ vs $13.8 \pm 3.0, \mathrm{p}<0.001$ for left hip). Dysplastic CE angles were recorded in $11.2 \%$ (26/232) of right contralateral hips and $16.2 \%$ (54/334) of left contralateral hips and in 2.1\% (23/1108) right control hips and $2.2 \%(24 / 1108)$ left control hips. Dysplastic ADs were found in $4.7 \%(11 / 232)$ of right contralateral hips and in $8.1 \%(27 / 334)$ of left contralateral hips. When compared with controls, univariate analysis indicated significantly higher risks of hip $\mathrm{OA}$ associated with dysplastic $\mathrm{CE}$ angle and $\mathrm{AD}$ in the contralateral hip in both women and men (table 3).

The results were supported by our adjusted analyses where both $\mathrm{CE}$ angle and $\mathrm{AD}$ were analysed together and remained as risk factors for hip OA after adjustment for right/left side, age, gender and BMI (figure 2). Compared with controls, an approximate eightfold risk was conferred by $\mathrm{CE}$ angle and a 2.5 -fold risk by $\mathrm{AD}$ (table 4). Hip dysplasia was associated with an increased risk of hip OA (CE angle: aOR $1.76,95 \%$ CI 1.48 to 2.08 , p trend $<0.001 ; \mathrm{AD}: \mathrm{aOR} 1.29,95 \%$ CI 1.08 to 1.53 , $\mathrm{p}$ trend $=0.004)$.

Table 2 Characterisation of hips in the two study groups

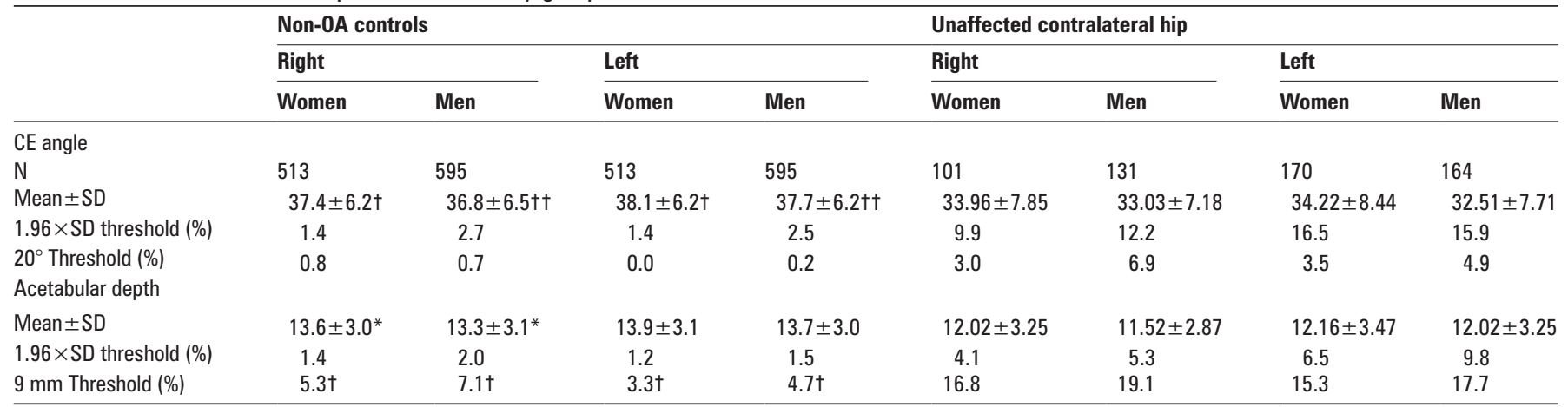

The right and left hips of non-OA controls show a small amount of asymmetry of CE angle and AD. The hip morphologies of women and men were mostly similar. Mean and SDs of each measure are presented with the prevalence of 'dysplastic' hips according to our threshold and standard criteria from the literature. Comparisons of right versus left continuous measures were performed using the paired $t$ test, while women were compared with men using the Student $t$ test. Comparisons of right versus left 'dysplastic' hips were performed using the McNemar test and women were compared with men using the $\chi^{2}$ test.

${ }^{*} \mathrm{p}<0.05$ women vs men.

$t p<0.05, \dagger t p<0.01$ right vs left hips within the same sex.

$0 \mathrm{~A}$, osteoarthritis. 
Table 3 Mild constitutional dysplasia of the contralateral hip and risks of OA

\begin{tabular}{|c|c|c|c|c|c|}
\hline \multirow[b]{3}{*}{ Measure } & \multirow[b]{3}{*}{ Threshold } & \multicolumn{4}{|c|}{ Univariate analysis: $\mathrm{OR}(95 \% \mathrm{Cl})$} \\
\hline & & \multicolumn{2}{|l|}{ Right } & \multicolumn{2}{|l|}{ Left } \\
\hline & & Women & Men & Women & Men \\
\hline CE angle & $20^{\circ}$ & 3.96 (0.65 to 24.08$)$ & NA & NA & $14.72(1.82 \text { to } 118.75)^{* *}$ \\
\hline \multirow[t]{2}{*}{$A D$} & Mean $-1.96 \times \mathrm{SD}$ & $2.65(0.65$ to 10.80$)$ & $3.19(1.16 \text { to } 8.75)^{*}$ & $7.81(1.69 \text { to } 36.12)^{* *}$ & $12.27(2.73 \text { to } 55.08)^{* *}$ \\
\hline & $9 \mathrm{~mm}$ & $4.20(1.93 \text { to } 9.15)^{* *}$ & $3.42(1.82 \text { to } 6.41)^{* *}$ & $6.32(2.68 \text { to } 14.92)^{* *}$ & $4.92(2.44 \text { to } 9.95)^{* *}$ \\
\hline
\end{tabular}

Univariate analysis of risks $(\mathrm{OR}(95 \% \mathrm{CI}))$ of hip $\mathrm{OA}$ determined using thresholds in unaffected contralateral hip acetabular morphology measures.

${ }^{*} \mathrm{p}<0.05,{ }^{* *} \mathrm{p}<0.01$.

$A D$, acetabular depth; $C E$, centre edge; $O A$, osteoarthritis.

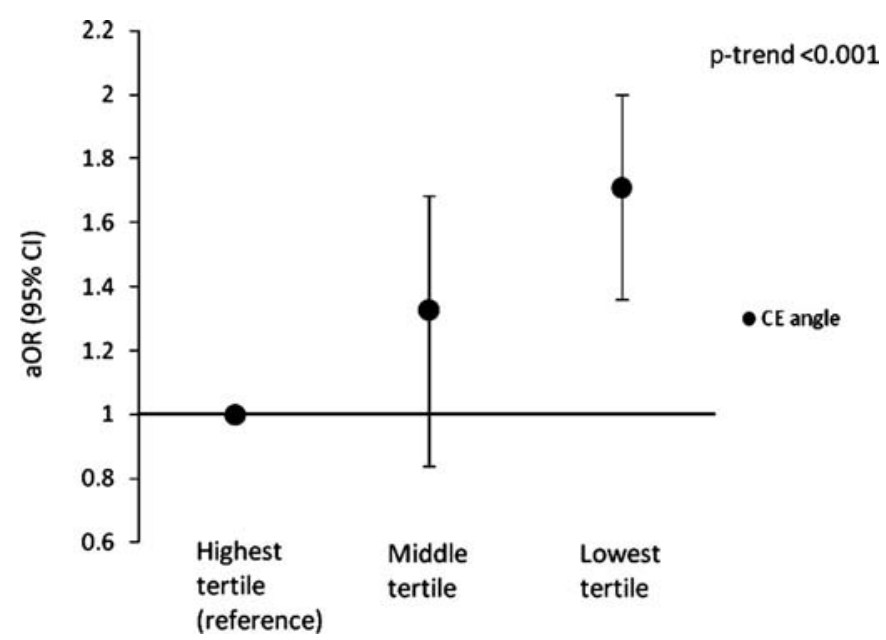

Figure 2 Increasing risk of hip osteoarthritis $(O A)$ with changes in the morphology of the unaffected contralateral hip. The risk of hip $0 \mathrm{~A}$ is increased as the tertiles for centre edge (CE) angle decrease. OR, $95 \% \mathrm{Cl}$ and $p$ trend were adjusted for age, gender, body mass index, acetabular depth and right/left hip.

Table 4 Increased risk of hip OA with low $A D$ and $C E$ angle

\begin{tabular}{|c|c|c|}
\hline & Threshold & $\mathrm{aOR}(95 \% \mathrm{Cl})$ \\
\hline \multirow[t]{2}{*}{ CE angle } & Mean $-1.96 \times$ SD & $8.06(4.87 \text { to } 13.35)^{* *}$ \\
\hline & $20^{\circ}$ & $10.05(2.89 \text { to } 35.01)^{* *}$ \\
\hline \multirow[t]{2}{*}{$A D$} & Mean-1.96×SD & $2.53(1.28 \text { to } 5.00)^{* *}$ \\
\hline & $9 \mathrm{~mm}$ & $3.61(2.47 \text { to } 5.27)^{* * *}$ \\
\hline
\end{tabular}

Increased risk of hip $0 \mathrm{~A}$, after adjustment for possible confounders, was associated with decreasing $A D$ and $C E$ angle. The risks for hip $\mathrm{OA}$ were associated with falling below the threshold for $\mathrm{CE}$ angle or $A D$ in the contralateral unaffected hip. Logistic regression was adjusted for left/right hip, AD, CE angle, age, gender and body mass index.

** $\mathrm{p}<0.01$

$A D$, acetabular depth; $C E$, centre edge; $O A$, osteoarthritis.

\section{DISCUSSION}

We found that $\mathrm{CE}$ angle and $\mathrm{AD}$ at the lowest extreme of the normal range in the unaffected contralateral hip were risk factors for OA. Also, as measures of $\mathrm{CE}$ angle and $\mathrm{AD}$ decreased, the risk of hip OA increased. Because hip disease presenting in childhood or young adulthood, including severe hip dysplasia, was excluded from the GOAL cohort, it appears that mild hip dysplasia may be a constitutional risk factor for some adults who develop clinically severe hip OA as adults. In the GOAL study population, other mild differences in morphology on the femoral side of the joint have also been found to be more common in the contralateral hips of those with unilateral hip OA, suggesting that morphological variation may be a biomechanical risk factor for 'common' OA presenting in adults. ${ }^{23}$

Our study supports the finding that mild hip dysplasia is associated with hip OA in Western European populations. ${ }^{311} 13$ Most literature relating to $\mathrm{CE}$ angle uses the thresholds $25^{\circ}$ or $20^{\circ}$ to define dysplasia, and a $9 \mathrm{~mm}$ threshold for $\mathrm{AD}$ is often used. ${ }^{816}$ Owing to the small asymmetry of the right and left non-OA control hips, we calculated our own thresholds to define dysplasia from the non-OA controls, as previously described. ${ }^{23}$ Right and left thresholds were numerically similar, implying that an approximation, or the mean of both, would have been adequate for our purposes. All hip x-rays were measured in a standardised way (as detailed earlier ${ }^{23}$ ), so this small asymmetry within the non-OA control group appears to be real, although it is possible that measurement error/variability could be responsible. The dominant side of participants is another plausible explanation, although hip dysplasia did not differ between those in the control group with right or left handedness. Our criteria for dysplastic CE angles were very close to the $25^{\circ}$ threshold used in many studies, and we also included data using a $20^{\circ}$ threshold for comparison purposes. Interestingly, the $20^{\circ}$ threshold excluded almost all control hips, suggesting that it is either extremely specific for dysplasia or may exclude positives. This resulted in variable ORs during univariate analysis, which are unlikely to be reliable. Instead, the thresholds closer to $25^{\circ}$ were superior for calculating risks. The criteria we used for acetabular dysplasia were considerably less than the $9 \mathrm{~mm}$ standard used in other studies, but both yielded similar findings. The use of the standard thresholds of $25^{\circ}$ for $\mathrm{CE}$ angle and $9 \mathrm{~mm}$ for $\mathrm{AD}$ appear to be justified, and their use in future studies seems appropriate.

The correlation found between age and CE angle has also been reported in other studies where hip OA in younger patients was associated with lower CE angle. ${ }^{16}$ The relationships between $\mathrm{CE}$ angle and $\mathrm{AD}$ with age appeared too weak to be clinically significant, despite their statistical significance. This was confirmed in our analyses where adjustments performed for age did not explain the association of hip morphology measurements with $\mathrm{OA}$. The correlation between $\mathrm{AD}$ and $\mathrm{CE}$ angle has been reported in other radiographic studies of the hip, ${ }^{16}$ and it is not surprising that they are related. Adjusting for CE angle and $\mathrm{AD}$ in the same logistic regression model showed that both are independent risk factors, despite their correlation. The risks conferred by $\mathrm{AD}$ were much closer to unity than those conferred by CE angle. Gender differences between hips were not especially prominent, in contrast to our previous study of hip morphology, ${ }^{23}$ with only right $\mathrm{AD}$ differing in the non-OA control group (table 3). Our univariate analyses separated gender and our multivariate analysis adjusted for gender, but it did not explain the risks for OA in this study.

This case-control study of patients with severe hip OA recruited participants from hospital lists with clinically severe 
OA. End stage cases increase the difficulty in investigating whether hip morphology is part of a developing OA or a preexisting constitutional risk factor. By focusing on the contralateral normal hip in people with unilateral hip OA, our findings provide evidence that $\mathrm{CE}$ angle and $\mathrm{AD}$ contribute towards causation. However, it is possible that these apparently normal asymptomatic hips might also be progressing towards $\mathrm{OA}$ themselves. Patients with unilateral hip OA may alter gait and the way they perform domestic/work activities to compensate for pain and limited function, meaning that the contralateral hips could be undergoing some degree of remodelling. Only a prospective study will be able to determine causes and effects of hip morphology on OA with certainty. However, hip OA may show some asymmetry with respect to JSW, which is narrower in left hips than in right hips of patients with hip $O A,{ }^{31}$ so it is possible that morphological variants may favour one side over the other and be asymmetrical, although the determinants for this remain unclear. In this case-control hospital-based study, those invited to participate as controls might be more likely to decline. However, response rates from the eligible populations were good for both cases and controls, minimising potential biases. It is unknown whether any controls were referred for IVU because of hip pain. Previous pain in or around the hip region was reported in $7 \%$ of controls (who were aware that the study investigated hip OA), although those who had current hip or knee symptoms or radiographic hip OA were excluded. A single-view plain x-ray is relatively insensitive for detecting mild OA changes, so some controls may have had mild early OA. However, any minor changes in the controls due to hip OA would be expected to reduce rather than inflate the estimate of risk conferred by $\mathrm{CE}$ angle and $\mathrm{AD}$.

In summary, this study supports the hypothesis that mild hip dysplasia is a constitutional risk factor for hip OA in adults. The measurement of changes in $\mathrm{CE}$ angle and $\mathrm{AD}$ may be useful to include as a potential risk factor in future prospective studies of hip $O A$.

Competing interests RAM is an employee of AstraZeneca UK, owns stocks for AstraZeneca UK and is named on a patent application for a gene associated with osteoarthritis.

Ethics approval This study was conducted with the approval of the Nottingham research ethics committee and all participants gave written informed consent.

Funding AstraZeneca UK funded the GOAL study sample and data collection. The Arthritis Research Council provided infrastructure support during the GOAL study (grant 14581).

Provenance and peer review Not commissioned; externally peer reviewed.

\section{REFERENCES}

1. Doherty M, Lohmander LS, Brandt KD. Osteoarthritis. 2nd edn. Oxford: Oxford University Press, 2003.

2. MacGregor AJ, Antoniades L, Matson M, et al. The genetic contribution to radiographic hip osteoarthritis in women: results of a classic twin study. Arthritis Rheum 2000;43:2410-16.
3. Lane NE, Lin P, Christiansen L, et al. Association of mild acetabular dysplasia with an increased risk of incident hip osteoarthritis in elderly white women: the study of osteoporotic fractures. Arthritis Rheum 2000;43:400-4.

4. Smith RW, Egger P, Coggon D, et al. Osteoarthritis of the hip joint and acetabular dysplasia in women. Ann Rheum Dis 1995;54:179-81.

5. Cooper C, Inskip H, Croft P, et al. Individual risk factors for hip osteoarthritis: obesity, hip injury, and physical activity. Am J Epidemiol 1998;147:516-22.

6. Harris WH. Etiology of osteoarthritis of the hip. Clin Orthop Relat Res 1986:20-33

7. Lievense AM, Bierma-Zeinstra SM, Verhagen AP, et al. Influence of hip dysplasia on the development of osteoarthritis of the hip. Ann Rheum Dis 2004;63:621-6.

8. Lane NE, Nevitt MC, Cooper C, et al. Acetabular dysplasia and osteoarthritis of the hip in elderly white women. Ann Rheum Dis 1997;56:627-30.

9. Lievense AM, Bierma-Zeinstra SM, Verhagen AP, et al. Prognostic factors of progress of hip osteoarthritis: a systematic review. Arthritis Rheum 2002;47:556-62.

10. Conrozier T, Jousseaume CA, Mathieu P, et al. Quantitative measurement of joint space narrowing progression in hip osteoarthritis: a longitudinal retrospective study of patients treated by total hip arthroplasty. Br J Rheumatol 1998;37:961-8.

11. Jacobsen S, Sonne-Holm S, Søballe K, et al. Hip dysplasia and osteoarthrosis: a survey of 4151 subjects from the Osteoarthrosis Substudy of the Copenhagen City Heart Study. Acta Orthop 2005;76:149-58.

12. Jacobsen S, Sonne-Holm S. Hip dysplasia: a significant risk factor for the development of hip osteoarthritis. A cross-sectional survey. Rheumatology (Oxford) 2005:44:211-18.

13. Reijman M, Hazes JM, Pols HA, et al. Acetabular dysplasia predicts incident osteoarthritis of the hip: the Rotterdam study. Arthritis Rheum 2005;52:787-93.

14. Jessel RH, Zurakowski D, Zilkens C, et al. Radiographic and patient factors associated with pre-radiographic osteoarthritis in hip dysplasia. J Bone Joint Surg Am 2009;91:1120-9.

15. Birrell F, Silman A, Croft P, et al. Syndrome of symptomatic adult acetabular dysplasia (SAAD syndrome). Ann Rheum Dis 2003;62:356-8.

16. Croft $\mathbf{P}$, Cooper $\mathrm{C}$, Wickham $\mathrm{C}$, et al. Osteoarthritis of the hip and acetabular dysplasia. Ann Rheum Dis 1991;50:308-10.

17. Okano K, Takaki M, Okazaki N, et al. Bilateral incidence and severity of acetabular dysplasia of the hip. J Orthop Sci 2008;13:401-4.

18. Inoue K, Wicart P, Kawasaki T, et al. Prevalence of hip osteoarthritis and acetabular dysplasia in French and Japanese adults. Rheumatology (Oxford) 2000;39:745-8.

19. Ali-Gombe A, Croft PR, Silman AJ. Osteoarthritis of the hip and acetabular dysplasia in Nigerian men. J Rheumatol 1996;23:512-15.

20. Lavy CB, Msamati BC, Igbigbi PS. Racial and gender variations in adult hip morphology. Int Orthop 2003;27:331-3.

21. Goker B, Sancak A, Haznedaroglu S. Radiographic hip osteoarthritis and acetabular dysplasia in Turkish men and women. Rheumatol Int 2005;25:419-22.

22. Johnsen $\mathbf{K}$, Goll $\mathrm{R}$, Reikerås 0 . Acetabular dysplasia as an aetiological factor in development of hip osteoarthritis. Int Orthop 2009;33:653-7.

23. Doherty M, Courtney P, Doherty S, et al. Nonspherical femoral head shape (pistol grip deformity), neck shaft angle, and risk of hip osteoarthritis: a case-control study. Arthritis Rheum 2008;58:3172-82.

24. Limer KL, Tosh K, Bujac SR, et al. Attempt to replicate published genetic associations in a large, well-defined osteoarthritis case-control population (the GOAL study). Osteoarthr Cartil 2009;17:782-9.

25. Robertson J, Zhang W, Liu JJ, et al. Radiographic assessment of the index to ring finger ratio (2D:4D) in adults. J Anat 2008;212:42-8.

26. Zhang $\mathbf{W}$, Robertson J, Doherty $\mathrm{S}$, et al. Index to ring finger length ratio and the risk of osteoarthritis. Arthritis Rheum 2008;58:137-44.

27. O'Reilly S, Johnson S, Doherty S, et al. Screening for hand osteoarthritis (OA) using a postal survey. Osteoarthr Cartil 1999;7:461-5.

28. Thaper A, Zhang W, Wright G, et al. Relationship between Heberden's nodes and underlying radiographic changes of osteoarthritis. Ann Rheum Dis 2005; 64:1214-16.

29. Wiberg G. A measuring method for distinguishing between a normal and a maldeveloped acetabulum. Acta Chir Scand 1939; 83:28-38.

30. Murray RO. The aetiology of primary osteoarthritis of the hip. Br J Radiol 1965;38:810-24.

31. Lanyon P, Muir K, Doherty S, et al. Age and sex differences in hip joint space among asymptomatic subjects without structural change: implications for epidemiologic studies. Arthritis Rheum 2003;48:1041-6. 


\section{ARD}

\section{Mild acetabular dysplasia and risk of osteoarthritis of the hip: a case-control study}

Daniel F McWilliams, Sally A Doherty, Wendy D Jenkins, et al.

Ann Rheum Dis 2010 69: 1774-1778 originally published online May 14, 2010

doi: 10.1136/ard.2009.127076

Updated information and services can be found at:

http://ard.bmj.com/content/69/10/1774.full.html

\section{These include:}

References This article cites 29 articles, 11 of which can be accessed free at: http://ard.bmj.com/content/69/10/1774.full.html\#ref-list-1

Email alerting Receive free email alerts when new articles cite this article. Sign up in service the box at the top right corner of the online article.

Topic Articles on similar topics can be found in the following collections Collections

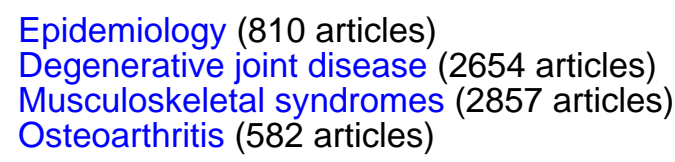

Notes

To request permissions go to:

http://group.bmj.com/group/rights-licensing/permissions

To order reprints go to:

http://journals.bmj.com/cgi/reprintform

To subscribe to BMJ go to:

http://group.bmj.com/subscribe/ 